\title{
ORTHODONTIC TREATMENT OUTCOME LITERACY: PERCEPTION OF RISKS AND BENEFITS
}

\author{
Khadijah A. Turkistani"
}

\begin{abstract}
Aim: To assess level of orthodontic outcome literacy in terms of risks and benefits among patients undergoing active treatment.

Materials and Methods: Descriptive cross-sectional study at King Abdulaziz University Faculty of Dentistry. Questionnaire was distributed to orthodontic patients using convenient sampling method. Demographics and perceptions of risks and benefits were collected. Descriptive statistics were reported in frequency and percentage.
\end{abstract}

Results: A total of 113 participants from KAUFD orthodontic clinics. Majority were 59\% females, $59 \%$ children and adolescents and $66 \%$ were Saudi. Referrals from $49 \%$ dentists, $30 \%$ selfreferral and $20 \%$ parents. The main reason for seeking treatment was $47 \%$ esthetics, $27 \%$ function and $13 \%$ stability. Respondents perceived orthodontic risks as 30\% painful, 55\% uncomfortable, $43 \%$ result in ulcer, $38 \%$ cause white spot lesion, $45 \%$ caries, $8 \%$ root resorption, $11 \%$ gingival recession, $38 \%$ mobility and $56 \%$ relapse while $75 \%$ believed in their role in preventing adverse events. They perceived benefits as $94 \%$ better smile, $90 \%$ better bite, $85 \%$ straight teeth, $60 \%$ teeth remain straight forever, $90 \%$ look better and $78 \%$ attractive profile. Reported previous knowledge $66 \%$ risks and $70 \%$ benefits and $20 \%$ signed a consent form.

Conclusion: Lack of orthodontic treatment outcome literacy could create an understanding barrier resulting in compromised compliance and treatment outcome. Findings recommended providing adequate information using consent form and proper communication about benefits and risks prior to initiating any orthodontic treatment. Further studies to evaluate effectiveness of such methods, compare perception to prevalence in terms of risks and benefits and their influence on treatment decision are recommended.

\section{INTRODUCTION}

Health literacy is defined by the US Department of Health and Human Services as "the degree to which individuals have the capacity to obtain, process, and understand basic health information and services needed to make appropriate health decisions". ${ }^{1}$ Low health literacy could adversely impact treatment decision and treatment outcome.

\footnotetext{
* Department of Orthodontics, Faculty of Dentistry, King Abdulaziz University, Jeddah, Saudi Arabia.
} 
Inability to fully comprehend and understand risks and benefits of undergoing treatment, and pros and cons of each treatment option would compromise individuals' conscious decision of undergoing such treatment. ${ }^{2}$ Health literacy among individuals could be worse than their general literacy, which makes it easier to improve communication skills of healthcare providers rather than altering the patients' ${ }^{1,3}$ Furthermore, suboptimal understanding of the information provided by health practitioners or those recorded within the informed consent could exacerbate treatment adverse events and subject individuals to harm rather than doing good.

In orthodontics, patients undergo treatment to enhance esthetics, stability and function. Improving esthetics and psychological wellbeing were reported to be among the main reasons for seeking orthodontic treatment. ${ }^{4}$ Attractive smile was reported to enhance patient's self-perception and psychological wellbeing. Well aligned teeth have been reported to positively influence social level. Improvement in self appearance has been reported to motivate individuals to undergo treatment. ${ }^{5} \mathrm{On}$ the other hand, treatment could relatively take a long period of time. This extended duration of orthodontic treatment could result in adverse events. Root resorption has been reported in previous studies to be strongly associated with prolonged duration of treatment. ${ }^{6}$ In addition, white spot lesion WSL is caused by plaque retention and compromised oral hygiene experienced during orthodontic treatment. ${ }^{7}$ This could result in demineralization of teeth and jeopardize esthetics that necessitate extensive restorative treatment later on, which could progress further leading to development of dental caries. ${ }^{8}$ Periodontal problems, gingival recession and dental mobility are possible complications of orthodontic therapy. ${ }^{9}$ These adverse events could be minimized by patients compliance and adequate oral hygiene measures. Keeping patients informed about risks and benefits of treatment outcome and their shared responsibility within the treatment process could enhance their engagement and improve compliance.
Success of orthodontic treatment not only depend on orthodontist skills but rather on patients' and their guardians' cooperation and compliance. ${ }^{10}$ Children were reported to have minimal knowledge about their orthodontic treatment. ${ }^{11}$ They were less likely to retain orthodontic information after the consultation visits compared to their parents. ${ }^{12}$ Therefore, incorporating a mixed approach in delivering information including verbal, written and audiovisual were recommended. ${ }^{13}$ Enhancing oral health literacy through effective communication prior to initiating any treatment is an essential element within the treatment process. This would facilitate understanding of patient's complaints, motivations and expectations that in turn help in treatment planning and post treatment satisfaction. ${ }^{14}$ A long with this communication, treatment benefits and risks of developing complications need to be addressed. Adequate explanation and providing information about adverse events before their occurrence help establish trust and makes it easier to deal with them later in case they arise. This information needs to be provided in written informed consents and explained verbally to patients in a language they understand. ${ }^{15}$ Lack of communication could create misunderstanding and ambiguity that might result in problems. To our knowledge, the literature lacks information about orthodontic outcome literacy in Saudi Arabia. For this, the aim of this study was to assess the level of orthodontic outcome literacy in terms of risks and benefits among patients undergoing active treatment. Results of this study could help provide valid recommendations to enhance practice management and patient care.

\section{MATERIALS AND METHODS}

This study was reviewed and approved by the Research Ethical Committee at the Faculty of Dentistry, King Abdulaziz University (KAUFD). It is a descriptive cross-sectional study that was performed at King Abdulaziz University Faculty of Dentistry (KAUFD) in Jeddah, Saudi Arabia. 
Convenient sampling technique was used on patients undergoing active orthodontic treatment. These patients were asked to fill a questionnaire while waiting for their appointment. All patients signed informed consents and participation was voluntary with no identifiers to keep information anonymous. Any patient with craniofacial anomaly or intellectual disability were excluded.

\section{Questionnaire:}

The questionnaire was in Arabic language and comprised of three components. The first component was dedicated for demographics including age, gender, educational background, referred by whom and the main reason for seeking treatment.

The second component composed of 29 items related to perception of orthodontic risks and benefits as an indicator of outcome literacy. These questions were adopted from McComb et al. ${ }^{16}$ that was initially developed at the University of Pittsburg, USA. The questions were translated into Arabic language using the World Health Organization WHO process of translation and adaptation. ${ }^{17}$ Forward-translation followed by bilingual expert panel back-translation was used. Lastly, the back-translated version was compared to the original and evaluated by the main author to ensure translation accuracy. Patients were given three options to choose from Yes/No/ Don't know. The third component had additional questions regarding previous knowledge and recommendation of risks and benefits. Descriptive statistics were reported in frequency and percentage using Microsoft Excel 2019 Software.

\section{RESULTS}

A total of 113 patients signed the consents and agreed to participate. Characteristics of study participants are presented in Table 1. Majority of respondents were females $59 \%$ compared to males $41 \%$. Children and adolescents comprised $59 \%$ of the respondents. Participants were predominantly Saudi
$66 \%$ compared to Non-Saudi $34 \%$. Of those who reported their educational background, $65 \%$ were in high school or below, followed by graduate $32 \%$ then postgraduate $3 \%$. Referral to the orthodontist was mainly initiated by dentist $49 \%$ followed by self-referral $30 \%$ and parents' referral $20 \%$. The main reported reason for seeking treatment was esthetics, function and stability comprising $47 \%$, $27 \%$ and $13 \%$ respectively.

TABLE (1) Characteristics of participants $(n=113)$

\begin{tabular}{|c|c|c|c|}
\hline \multicolumn{2}{|c|}{ Variable } & \multirow{2}{*}{$\begin{array}{c}\text { Frequency } \\
(\%)\end{array}$} & \multirow{3}{*}{$\begin{array}{c}\begin{array}{c}\text { Total } \\
\text { Response } \\
(\%)\end{array} \\
111(98 \%)\end{array}$} \\
\hline \multirow{2}{*}{ Gender } & Male & & \\
\hline & Female & $65(59 \%)$ & \\
\hline \multirow{5}{*}{ Age } & $<15$ & $29(27 \&)$ & \multirow{5}{*}{$108(96 \%)$} \\
\hline & $16-20$ & $34(32 \%)$ & \\
\hline & $21-25$ & $22(20 \%)$ & \\
\hline & $26-30$ & $14(13 \%)$ & \\
\hline & $>30$ & $9(8 \%)$ & \\
\hline \multirow{2}{*}{ Nationality } & Saudi & $68(66 \%)$ & \multirow{2}{*}{$103(91 \%)$} \\
\hline & Non-Saudi & $35(34 \%)$ & \\
\hline \multirow{3}{*}{$\begin{array}{l}\text { Educational } \\
\text { Background }\end{array}$} & $\begin{array}{l}\text { High school } \\
\text { and less }\end{array}$ & $68(65 \%)$ & \multirow{3}{*}{$104(92 \%)$} \\
\hline & Graduate & $33(32 \%)$ & \\
\hline & Postgraduate & $3(3 \%)$ & \\
\hline \multirow{3}{*}{ Referred by } & Self & $33(30 \%)$ & \multirow{3}{*}{$111(98 \%)$} \\
\hline & Parents & $24(21 \%)$ & \\
\hline & Dentist & $54(49 \%)$ & \\
\hline \multirow{4}{*}{$\begin{array}{l}\text { Reasons } \\
\text { for seeking } \\
\text { treatment }\end{array}$} & Esthetic & $50(47 \%)$ & \multirow{4}{*}{$107(95 \%)$} \\
\hline & Function & $29(27 \%)$ & \\
\hline & Stability & $14(13 \%)$ & \\
\hline & Others & $14(13 \%)$ & \\
\hline
\end{tabular}

Table 2 presents participants perceptions of orthodontic risks. Around $30 \%$ of respondents perceived orthodontics as painful compared to $56 \%$ who don't. Around 55\% felt that braces were uncomfortable and could result in ulcer 43\%. Majority of patients did not feel that braces could result in WSL $38 \%$ or caries $45 \%$. From the respondents' group, only $8 \%$ believed that 
orthodontic treatment could result in root resorption, $11 \%$ believed it will cause gingival recession and $38 \%$ will cause dental mobility. A high percentage of respondents were aware of future relapse $56 \%$ and $75 \%$ believed that they have a role in preventing treatment adverse events.

Respondents reported high perception of better smile $94 \%$ and better bite $90 \%$ after treatment (Table $3)$. They thought they will have straight teeth after orthodontic treatment $85 \%$ and the teeth will remain straight forever $60 \%$. Most of the respondents believed they will look better as a result of treatment $90 \%$ with more attractive profile $78 \%$.
When patients were asked if they knew about orthodontic risks, $66 \%$ confirmed their knowledge compared to $29 \%$ who denied it and $5 \%$ who were unsure. Around $84 \%$ believed its essential to receive this information prior to initiate treatment while 9\% did not believe its important. When they were asked if they had prior knowledge about orthodontic benefits, $70 \%$ reported previous knowledge compared to $25 \%$ who didn't. About $90 \%$ believed it's important to have information about orthodontic benefits prior to initiating treatment compared to $5 \%$ who don't. When they were asked if they signed an informed consent containing this information, 20\% of the respondents reported signing a consent while $69 \%$ didn't and $11 \%$ were unsure.

TABLE (2) Perception of orthodontic risks ( $n=113$ )

\begin{tabular}{|c|c|c|c|c|}
\hline Questionnaire item & Yes $(\%)$ & No $(\%)$ & $\begin{array}{c}\text { Don't Know } \\
(\%)\end{array}$ & $\begin{array}{c}\text { Total Response } \\
(\%)\end{array}$ \\
\hline Experience pain during orthodontic appointment & $34(30 \%)$ & $63(56 \%)$ & $15(14 \%)$ & $112(99 \%)$ \\
\hline Experience pain few days after orthodontic appointment & $52(47 \%)$ & $43(38 \%)$ & $17(15 \%)$ & $112(99 \%)$ \\
\hline Breakage of a piece of bracket & $42(37 \%)$ & $41(37 \%)$ & $29(26 \%)$ & $112(99 \%)$ \\
\hline Gum swelling during orthodontic treatment & $28(26 \%)$ & $57(53 \%)$ & $22(21 \%)$ & $107(95 \%)$ \\
\hline Teased about having braces & $7(6 \%)$ & $97(88 \%)$ & $6(6 \%)$ & $110(97 \%)$ \\
\hline Extraction of some teeth & $78(70 \%)$ & $22(20 \%)$ & $11(10 \%)$ & $111(98 \%)$ \\
\hline Braces might look funny on you & $16(14 \%)$ & $81(72 \%)$ & $15(14 \%)$ & $112(99 \%)$ \\
\hline Swallow a piece of braces & $12(11 \%)$ & $71(66 \%)$ & $25(23 \%)$ & $108(96 \%)$ \\
\hline Sores or ulcers from braces & $48(43 \%)$ & $27(24 \%)$ & $36(33 \%)$ & $111(98 \%)$ \\
\hline Feel uncomfortable & $60(55 \%)$ & $41(37 \%)$ & $9(8 \%)$ & $110(97 \%)$ \\
\hline White spot lesion (Decalcification) & $33(29 \%)$ & $42(38 \%)$ & $37(33 \%)$ & $112(99 \%)$ \\
\hline Caries & $41(37 \%)$ & $50(45 \%)$ & $20(18 \%)$ & $111(98 \%)$ \\
\hline Root resorption & $8(7 \%)$ & $62(56 \%)$ & $41(37 \%)$ & $111(98 \%)$ \\
\hline Allergic reaction & $26(24 \%)$ & $57(52 \%)$ & $27(24 \%)$ & $110(97 \%)$ \\
\hline Teeth mobility & $41(38 \%)$ & $45(41 \%)$ & $23(21 \%)$ & $109(97 \%)$ \\
\hline Relapse (recurrence) & $62(56 \%)$ & $20(18 \%)$ & $29(26 \%)$ & $111(98 \%)$ \\
\hline Gingival recession & $12(11 \%)$ & $47(43 \%)$ & $51(46 \%)$ & $110(97 \%)$ \\
\hline Enamel fracture during debonding & $12(11 \%)$ & $52(47 \%)$ & $47(42 \%)$ & $111(98 \%)$ \\
\hline You have a role in preventing adverse events & $82(75 \%)$ & $10(9 \%)$ & $18(16 \%)$ & $110(97 \%)$ \\
\hline
\end{tabular}


TABLE (3) Perception of orthodontic benefits $(n=113)$

\begin{tabular}{|l|c|c|c|c|}
\hline \multicolumn{1}{|c|}{ Questionnaire item } & Yes $(\%)$ & No (\%) & $\begin{array}{c}\text { Don't Know } \\
(\%)\end{array}$ & $\begin{array}{c}\text { Total Response } \\
(\%)\end{array}$ \\
\hline Better smile as a result of orthodontic treatment & $104(94 \%)$ & $1(1 \%)$ & $6(5 \%)$ & $111(98 \%)$ \\
\hline Better bite after orthodontic treatment & $100(90 \%)$ & $5(5 \%)$ & $5(5 \%)$ & $110(97 \%)$ \\
\hline Look better after orthodontic treatment & $101(91 \%)$ & $1(1 \%)$ & $9(8 \%)$ & $111(98 \%)$ \\
\hline $\begin{array}{l}\text { Teeth will be easier to brush as a result of orthodontic } \\
\text { treatment }\end{array}$ & $86(78 \%)$ & $10(9 \%)$ & $14(13 \%)$ & $110(97 \%)$ \\
\hline Straight teeth forever & $66(60 \%)$ & $16(15 \%)$ & $28(25 \%)$ & $110(97 \%)$ \\
\hline Straight teeth after treatment & $94(85 \%)$ & $5(5 \%)$ & $12(10 \%)$ & $111(98 \%)$ \\
\hline More attractive profile & $86(78 \%)$ & $2(2 \%)$ & $22(20 \%)$ & $110(97 \%)$ \\
\hline Teeth will look better as a result of braces & $99(90 \%)$ & $5(5 \%)$ & $5(5 \%)$ & $109(97 \%)$ \\
\hline Less dental decay & $52(48 \%)$ & $30(27 \%)$ & $27(25 \%)$ & $109(97 \%)$ \\
\hline $\begin{array}{l}\text { Pleased and happy with the way you look after } \\
\text { orthodontic treatment }\end{array}$ & $84(77 \%)$ & $7(6 \%)$ & $19(17 \%)$ & $110(97 \%)$ \\
\hline
\end{tabular}

\section{DISCUSSION}

Lack of health literacy could create an understanding barrier that compromise individual's ability to comprehend information and make accurate decisions. This could adversely affect compliance to treatment and result in dissatisfaction and resentment with treatment outcome. Incorporating verbal, audiovisual and written methods in delivering information to patients was recommended by Stephens et al. ${ }^{13}$ Morthensen et al. reported that children together with their guardians recall significantly less information about reasons to undergo treatment, risks associated with such treatment and their obligations during treatment compared to what the orthodontist informed them. ${ }^{18}$ This would question the effectiveness of the current informed consent methods used especially with regards to the critical treatment risks including caries, periodontal problems and relapse.

In this study, the aim was to evaluate orthodontic treatment literacy among patients undergoing active orthodontic treatment at KAUFD in terms of risks and benefits. Majority of the study sample expected their facial appearance to look better with a more attractive profile and better looking teeth. This is in line with the findings of McComb et al. who reported optimistic views of patient's guardians to orthodontic health benefits compared to Addy et al. who reported lack of benefits to undergoing such treatment. ${ }^{16}$

Only $29 \%$ of patients expected to develop white spot lesion WSL. This contradicts the findings of Richter et al. who reported development of WSL in more than $70 \%$ of patients. In their study, they reported cavitation and significant association of WSL with length of treatment. ${ }^{19}$ Furthermore, only $26 \%$ of patients felt they will have gum swelling and inflammation. Previous studies have reported periodontal complications related to orthodontic treatment. Hadler-Olsen et al. reported a significant difference in WSL index of 1.9 in the orthodontic group compared to 0.4 in their matched controls. Additionally, a highly significant increase in the mean gingival bleeding index in the orthodontic group of $4.4 \%$ in comparison to $0.5 \%$ decrease in their controls. ${ }^{20}$ Moreover, in their systematic 
review, Verrusio et al. reported an elevation in periodontal parameters with orthodontic therapy that indicates accumulation of gingival microbiota leading to periodontal inflammation and bleeding on probing. They recommended placing orthodontic patients on regular hygiene visits following strict control. ${ }^{21}$ Additionally, $11 \%$ of the study population reported perception of gingival recession which is comparable to the findings of Morris et al. study, who concluded that orthodontic therapy was not a major risk in developing gingival recession. A little more than $5 \%$ of their study sample developed recession by end of treatment. ${ }^{22}$

In the current study, less than $50 \%$ of participants knew that they would experience pain after orthodontic appointment. However, Compos et al. reported that $50 \%$ of pediatric patients and $70 \%$ of adults experience pain after bracket bonding visit compared to $70 \%$ reported by both groups after archwire placement. ${ }^{23}$ Tuncer et al. reported pain associated with wearing intermaxillary elastics that starts 2 hours after elastic application and peaks within 6 hours then subsides the following day. ${ }^{24}$ Patients need to be aware of the pain they will experience before they start the treatment, or else once they would panic and consider it an emergency that necessitate contacting the orthodontist. About two thirds of patients in the current study reported previous knowledge of risks and benefits yet only $20 \%$ reported signing an informed consent. In ability to recall signing a consent could indicate failure to recall its content. Lastly, more than $80 \%$ of participants thought it would be beneficial to know risks and benefits prior to initiating any orthodontic treatment.

One of the limitations of the study is the convenient sampling technique that included patients from one center in Jeddah. However, we intend to develop policies and recommendations that improve clinical performance and practice management system within the orthodontic clinics at KAUFD. For this, we restricted the study sample on patients vising our clinics.
Overall, participants in the current study seem to have low perceptions of treatment risks and high perceptions of treatment benefits. This could be a result of the age group of the study sample. Majority of them were children and adolescents who are considered vulnerable population that need extra attention and care to ensure safety and adequate information delivery. In general, children need to sign assents in addition to the informed consents signed by their guardians. As mentioned earlier, health literacy of individuals could be less than general literacy. Considering findings of the current study, we recommend using informed consents including risks and benefits that is written in simple language and incorporating visual aids as pictures to simplify their meanings and capture reader's attention. This is preferably augmented by verbal explanation of the contents from the orthodontist or the orthodontic assistance. Finally, enhancing patients' literacy and education on treatment outcome are necessities in any successful orthodontic practice.

\section{CONCLUSION}

In summary, lack of orthodontic treatment outcome literacy among patients undergoing active treatment could create an understanding barrier that jeopardize compliance and compromise treatment outcome. Findings of this study recommends providing patients with adequate information about treatment benefits and risks prior to initiating any treatment. This information needs to be communicated well with patients making sure they understand it using different communication methods. Further studies to evaluate effectiveness of these methods on treatment outcome after debond and completion of treatment are recommended. Comparison of risks and benefits perception to actual prevalence of such events and the influence of these perceptions on treatment decision need to be studied in the future. 


\section{REFERENCES}

1. Merriman B, Ades T, Seffrin JR. Health literacy in the information age: communicating cancer information to patients and families. CA: A cancer journal for clinicians. 2002;52(3):130-133.

2. Davis TC, Williams MV, Marin E, Parker RM, Glass J. Health literacy and cancer communication. CA: a cancer journal for clinicians. 2002;52(3):134-149.

3. Association AM. Ad Hoc Committee on Health Literacy for the Council on Scientific Affairs.(1999). Health literacy: Report of the council on scientific affairs. Journal of the American Medical Association. 281(6):552-557.

4. Albino J, Cunat J, Fox R, Lewis E, Slakter M, Tedesco L. Variables discriminating individuals who seek orthodontic treatment. Journal of Dental Research. 1981;60(9):1661-1667.

5. Agou S, Locker D, Muirhead V, Tompson B, Streiner DL. Does psychological well-being influence oral-health-related quality of life reports in children receiving orthodontic treatment? American journal of orthodontics and dentofacial orthopedics. 2011;139(3):369-377.

6. Jiang R-p, McDonald J, Fu M-k. Root resorption before and after orthodontic treatment: a clinical study of contributory factors. The European Journal of Orthodontics. 2010;32(6):693-697.

7. Tufekci E, Dixon JS, Gunsolley J, Lindauer SJ. Prevalence of white spot lesions during orthodontic treatment with fixed appliances. The Angle Orthodontist. 2011;81(2):206-210.

8. Øgaard B, Rølla G, Arends J. Orthodontic appliances and enamel demineralization: Part 1. Lesion development. American Journal of Orthodontics and Dentofacial Orthopedics. 1988;94(1):68-73.

9. Alfuriji S, Alhazmi N, Alhamlan N, et al. The effect of orthodontic therapy on periodontal health: A review of the literature. International Journal of Dentistry. 2014;2014

10. Nanda RS, Kierl MJ. Prediction of cooperation in orthodontic treatment. American Journal of Orthodontics and Dentofacial Orthopedics. 1992;102(1):15-21.

11. Habibian M, Gelbier S, Munday B. Perceived information needs in respect of orthodontics amongst 11-12-year-old girls: a study through health visitor sessions in schools. International journal of paediatric dentistry. 2003;13(5):348-355.

12. Thomson AM, Cunningham SJ, Hunt NP. A comparison of information retention at an initial orthodontic consultation. The European Journal of Orthodontics. 2001;23(2):169-178.

13. Stephens R, Ryan FS, Cunningham SJ. Information-seeking behavior of adolescent orthodontic patients. Ameri- can Journal of Orthodontics and Dentofacial Orthopedics. 2013;143(3):303-309.

14. Souza RAd, Oliveira AFd, Pinheiro SMS, Cardoso JP, Magnani MBBdA. Expectations of orthodontic treatment in adults: the conduct in orthodontist/patient relationship. Dental press journal of orthodontics. 2013;18(2):88-94.

15. Carr KM, Fields Jr HW, Beck FM, et al. Impact of verbal explanation and modified consent materials on orthodontic informed consent. American journal of orthodontics and dentofacial orthopedics. 2012;141(2):174-186.

16. McComb J, Wright J, Fox N, O'Brien K. Perceptions of the risks and benefits of orthodontic treatment. Community dental health. 1996;13(3):133-138.

17. World Health Organization. Process of translation and adaptation of Instruments. 2013 [cited 2020 Jul 17] Available from: https://www.who.int/substance_abuse/research_tools/ translation/en/.

18. Mortensen MG, Kiyak HA, Omnell L. Patient and parent understanding of informed consent in orthodontics. American Journal of Orthodontics and Dentofacial Orthopedics. 2003;124(5):541-550.

19. Richter AE, Arruda AO, Peters MC, Sohn W. Incidence of caries lesions among patients treated with comprehensive orthodontics. American Journal of Orthodontics and Dentofacial Orthopedics. 2011;139(5):657-664.

20. Hadler-Olsen S, Sandvik K, El-Agroudi MA, Øgaard B. The incidence of caries and white spot lesions in orthodontically treated adolescents with a comprehensive caries prophylactic regimen - a prospective study. The European Journal of Orthodontics. 2012;34(5):633-639.

21. Verrusio C, Iorio-Siciliano V, Blasi A, Leuci S, Adamo D, Nicolò M. The effect of orthodontic treatment on periodontal tissue inflammation: A systematic review. Quintessence International. 2018;49(1).

22. Campos MJdS, Fraga MR, Raposo NRB, Ferreira AP, Vitral RWF. Assessment of pain experience in adults and children after bracket bonding and initial archwire insertion. Dental press journal of orthodontics. 2013;18(5):32-7.

23. Morris JW, Campbell PM, Tadlock LP, Boley J, Buschang $\mathrm{PH}$. Prevalence of gingival recession after orthodontic tooth movements. American Journal of Orthodontics and Dentofacial Orthopedics. 2017;151(5):851-9.

24. Tuncer Z, Ozsoy FS, Polat-Ozsoy O. Self-reported pain associated with the use of intermaxillary elastics compared to pain experienced after initial archwire placement. The Angle Orthodontist. 2011;81(5):807-11. 